\title{
Body Shaping and Volume Restoration: The Role of Hyaluronic Acid
}

\author{
Per Hedén · Gabriella Sellman • Mats von Wachenfeldt • \\ Michael Olenius · Dan Fagrell
}

Received: 27 June 2008/ Accepted: 2 December 2008/Published online: 12 March 2009

(c) The Author(s) 2009. This article is published with open access at Springerlink.com

\begin{abstract}
Driven by the rising popularity of minimally invasive techniques, the demand for cosmetic procedures is increasing. Cosmetic body-shaping procedures can be categorized into those that remove tissue and those that add volume. This review focuses on the latter of these categories, particularly on the use of resorbable hyaluronic acid gels specifically developed for minimally invasive volume enhancement. Pilot studies of hyaluronic acid involving its injection to contour various body deformities and its recent use in female breast augmentation are discussed. Injectable hyaluronic acid is effective and well tolerated. It represents an attractive treatment option for volume restoration or augmentation by providing predictable long-lasting results after minimally invasive administration. Alternative treatment options for volume enhancement also are summarized including fat transfer, silicone implants, and the use of injectable nonresorbable products such as silicone, polyalkylimide, and polyacrylamide gels. As patients continue to opt for nonsurgical procedures that offer predictable results, the development of minimally invasive products such as hyaluronic acid is increasingly important.
\end{abstract}

P. Hedén $(\bowtie) \cdot$ M. von Wachenfeldt

Akademikliniken, Storängsvägen 10, 11542 Stockholm, Sweden

e-mail: per.heden@ak.se

G. Sellman

Plastikkirurggruppen Sabbatsberg AB, Dalagatan 9,

11324 Stockholm, Sweden

M. Olenius

Proforma Clinic AB, Rosenlundsg. 29 A, 11863 Stockholm,

Sweden

D. Fagrell

Göteborgs Plastikkirurgiska Center, Fridkullagatan 35,

41265 Göteborg, Sweden
Keywords Breast augmentation - Fat grafts · Hyaluronic acid · Implants · Injectable fillers · Pilot studies $\cdot$ Silicone $\cdot$ Surgery alternatives

The skills developed to treat injuries sustained during World War II currently are applied extensively to those born in subsequent decades. "Baby boomers," individuals born in the 1940s, 1950s, and early 1960s, are increasingly turning to cosmetic surgery to improve their appearance. In the United States, individuals 40 years of age or older comprise $71 \%$ of all the patients who underwent cosmetic surgery during 2006 [3].

In 2006 compared with 2005, patients ages 40-54 years and 55 years or older respectively underwent $9 \%$ and $8 \%$ more cosmetic procedures. However, the rise in demand for cosmetic surgery procedures is not limited to older groups. Indeed, in 2007, the single greatest increase in demand for procedures was among those 20 to 29 years of age [3]. Confirming the interest in aesthetic interventions shown by younger groups despite their possession and advantage of "youth," $22 \%$ of all cosmetic procedures undertaken in 2006 were performed for those 19 to 34 years of age [2]. The rise in minimally invasive cosmetic procedures has driven the overall growth in cosmetic surgery $[2,3]$.

This review focuses on the use of hyaluronic acid for body contouring and breast augmentation. It also briefly discusses the range of alternative treatment options for body reshaping (summarized in Table 1).

\section{Hyaluronic Acid}

Stabilized hyaluronic acid of nonanimal origin NASHA $^{\mathrm{TM}}$ gel; Q-Med AB, Uppsala, Sweden) was developed using 
Table 1 Summary of advantages and disadvantages of procedures/products used to create volume in the body

\begin{tabular}{|c|c|c|}
\hline Intervention & Advantages & Disadvantages \\
\hline \multicolumn{3}{|c|}{ Autologous procedures } \\
\hline Injectable fat & $\begin{array}{l}\text { Potential for lasting durability } \\
\text { Versatile (can be used for a wide variety of indications) } \\
\text { Can be used in combination with liposuction to sculpt body } \\
\text { Filler completely biocompatible } \\
\text { Potential to regenerate surrounding tissues }\end{array}$ & $\begin{array}{l}\text { Unpredictability of cosmetic results } \\
\text { Unpredictability of fat survival } \\
\text { Donor site morbidity } \\
\text { Time consuming process }\end{array}$ \\
\hline $\begin{array}{l}\text { Segmental fat } \\
\text { transfer }\end{array}$ & Long-lasting graft survival & $\begin{array}{l}\text { Requires appropriate donor site, so not suitable } \\
\text { for many indications } \\
\text { Donor site subject to considerable morbidity and } \\
\quad \text { scarring } \\
\text { Time-consuming, complex procedure } \\
\text { Requires general anaesthesia } \\
\text { Extensive downtime } \\
\text { Costly }\end{array}$ \\
\hline Flap surgery & Long-lasting graft survival & $\begin{array}{l}\text { Requires appropriate donor site, so not suitable } \\
\quad \text { for many indications } \\
\text { Donor site subject to considerable morbidity and } \\
\quad \text { scarring } \\
\text { Time-consuming, complex procedure } \\
\text { Requires general anaesthesia } \\
\text { Extensive downtime } \\
\text { Costly }\end{array}$ \\
\hline
\end{tabular}

\section{Allogeneous procedures}

Silicone implants

Very long-lasting correction

No donor site required

Can be used to create substantial volume

Less downtime involved compared with flap surgery

Less complex and time-consuming compared with flap surgery

Injectable Long-lasting correction

silicone Requires no donor site

Minimally invasive: little downtime, use of general anaesthetic not required, can be carried out in an office environment, quick, relatively inexpensive

Polyalkylimide gel

Long-lasting correction

Requires no donor site

Minimally invasive: little downtime, use of general anaesthetic not required, can be carried out in an office environment, quick, relatively inexpensive Versatile

Polyacrylamide Long-lasting correction gel Requires no donor site

Minimally invasive: little downtime, use of general anaesthetic not required, can be carried out in an office environment, quick, relatively inexpensive

Versatile

Macrolane $^{\mathrm{TM}}$
VRF

Requires no donor site

Minimally invasive: little downtime, use of general anaesthetic not required, can be carried out in an office environment, quick, relatively inexpensive

NASHA $^{\mathrm{TM}}$ gels used in facial rejuvenation associated with a solid safety record

Versatile
Risk of rupture and other serious side effects

Not suitable to correct small concavities

More downtime required compared with minimally invasive procedures

More costly than minimally invasive procedures

Questionable long-term safety

Little empirical evidence regarding safety and efficacy in the peer-reviewed literature

Cannot be used to create larger volumes in the body

Questionable long-term safety

Little empirical evidence regarding safety and efficacy in the peer-reviewed literature

Questionable long-term safety

Little empirical evidence regarding safety and efficacy in the peer-reviewed literature

Correction is not permanent 
patented technology. A number of NASHA-based products, approved by the Food and Drug Administration (FDA), have been studied extensively for facial tissue augmentation in both the United States and Europe [5, 6, $10,15,16,36]$.

Hyaluronic acid, a naturally occurring polysaccharide, is a ubiquitous component of all mammalian connective tissues [20]. The chemical structure of hyaluronic acid is consistent across species, so potential for immunologic reactions is minimal when hyaluronic acid is used as a skin filler [31]. As hyaluronic acid is naturally and gradually degraded, the potential problems associated with permanent fillers, such as the permanency of incorrect injections or technical errors, are not applicable. Hyaluronic acid can be removed easily with the use of hyaluronidase.

To address the need for an injectable, biocompatible, and resorbable filler to enhance body contours, a new NASHA-based medical implant, Macrolane ${ }^{\mathrm{TM}}$ (Q-Med AB), was developed and approved in Europe in 2006. More recently, two improved versions of Macrolane with two different volume restoration factors (VRF) that have broader indications, Macrolane VRF20 and VRF30, have received CE marks. These novel products are indicated for volume restoration and contouring of body surfaces. Whereas VRF30 is intended primarily for deep subcutaneous administration, VRF20 (a thinner NASHA gel) is intended for more superficial subcutaneous injection.
A nonrandomized, open-label pilot study was conducted recently to explore the efficacy, duration of effect, and tolerability of the initial Macrolane formulation for recontouring body deformities of different etiologies (irregularities after liposuction and scars arising from trauma or surgery). The study was approved by the ethical committee at the Karolinska Institute in Stockholm. Using a 12-gauge cannula, Macrolane was injected supraperiostally and/or into the subcutaneous fatty tissue, then spread into the area to be augmented. Patients initially were treated with Macrolane $(\leq 20 \mathrm{ml})$, with an optional "touchup" treatment given 4 weeks later.

An example of a concave deformity correction using Macrolane is illustrated in Fig. 1. Efficacy was assessed independently by patients and investigators at 4 weeks, then 3, 6, 9, and 12 months after the last treatment using the Global Esthetic Improvement Scale (GEIS). The proportion of patients rated as improved (somewhat improved, moderately improved, or very much improved) was calculated using the "intention-to-treat" approach in an "observed case" manner (i.e., no imputations were made for missing data).

Of the 56 patients recruited, 46 completed the study. The patients initially received a mean Macrolane volume of $16.6 \pm 8.5 \mathrm{ml}$. "Touch-up" treatment was performed for 16 of the 56 patients, who received a mean gel volume of $14.7 \pm 4.9 \mathrm{ml}$. The proportions of improved patients, as assessed by the study investigators, were $87 \%$ at 4 weeks,
Fig. 1 Correction of a body concave deformity by Macrolane injection. a Patient before treatment. b Patient

3 months after treatment
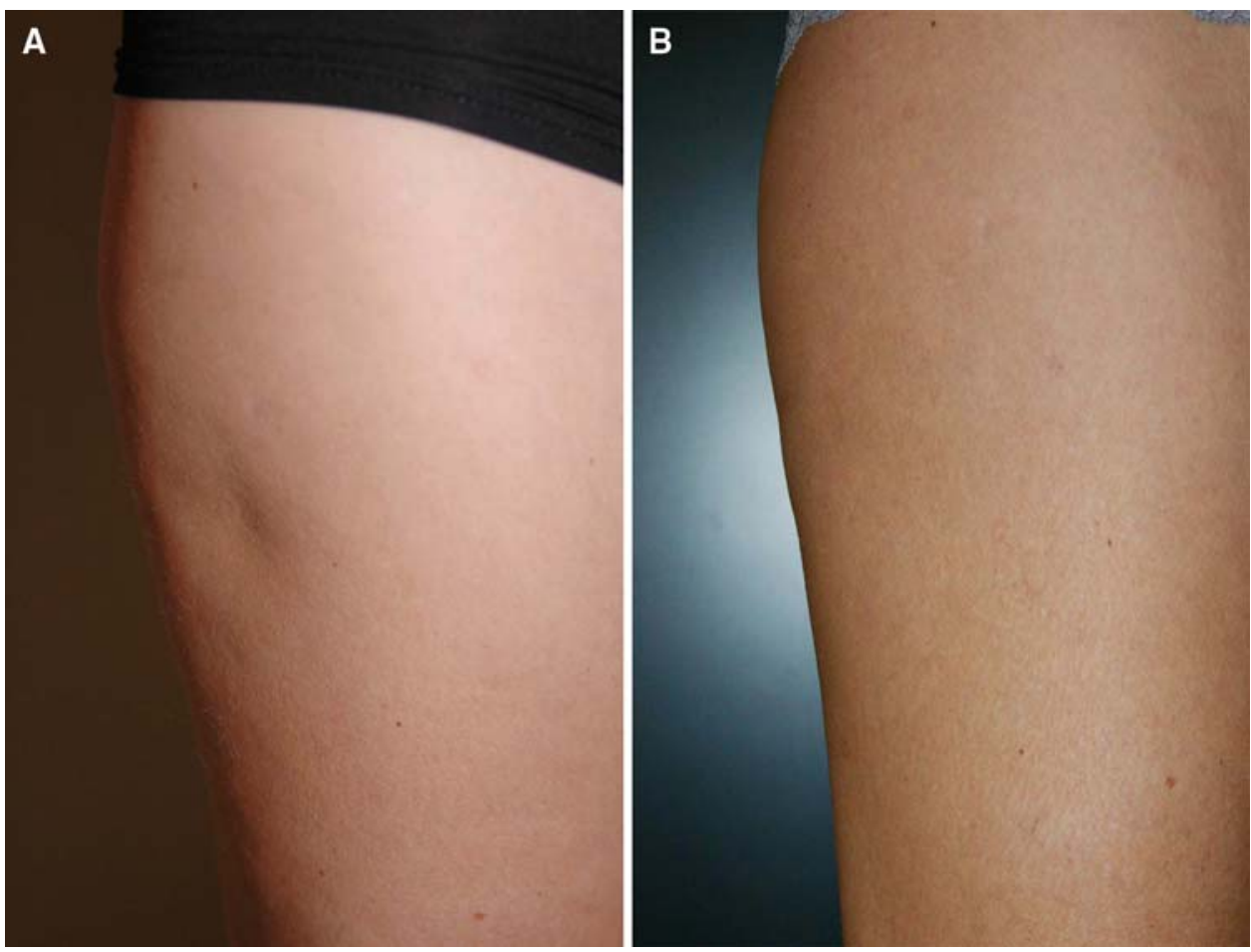
Table 2 Improvement of body shape after hyaluronic acid (HA) injection, as assessed by the investigator and patients, using the Global Esthetic Improvement Scale (GEIS)

\begin{tabular}{|c|c|c|c|c|}
\hline & \multirow{2}{*}{$\begin{array}{l}\text { Time after HA } \\
\text { injection }\end{array}$} & \multicolumn{3}{|c|}{ Proportion of patients (\%) } \\
\hline & & $\begin{array}{l}\text { Somewhat } \\
\text { improved }\end{array}$ & $\begin{array}{l}\text { Moderately } \\
\text { improved }\end{array}$ & $\begin{array}{l}\text { Very much } \\
\text { improved }\end{array}$ \\
\hline \multirow[t]{5}{*}{ Investigator-assessed } & 4 weeks & 13.2 & 24.5 & 49.1 \\
\hline & 3 months & 23.6 & 36.4 & 25.5 \\
\hline & 6 months & 26.9 & 26.9 & 15.4 \\
\hline & 9 months & 38.6 & 25.0 & 11.4 \\
\hline & 12 months & 23.9 & 23.9 & 4.3 \\
\hline \multirow[t]{5}{*}{ Patient-assessed } & 4 weeks & 20.8 & 28.3 & 32.1 \\
\hline & 3 months & 29.1 & 27.3 & 23.6 \\
\hline & 6 months & 38.5 & 13.5 & 17.3 \\
\hline & 9 months & 38.6 & 15.9 & 15.9 \\
\hline & 12 months & 28.3 & 21.7 & 6.5 \\
\hline
\end{tabular}

women aged 25 to 40 years with small breasts and seeking small-to-moderate augmentation were included in the study. Macrolane was injected at a level anterior to the pectoralis major muscle and posterior to the mammary gland using a 12-gauge needle. All the patients underwent clinical examinations, magnetic resonance imaging (MRI), mammography, and ultrasound scans. The patients were followed up for 48 months, and data from this period currently are being evaluated.

At the initial treatment session, 19 patients were injected with 80 to $100 \mathrm{ml}$ of Macrolane per breast. Seven patients received touch-up treatment $(20 \mathrm{ml})$ for a total of 12 breasts. The mean total volume injected per patient, in both breasts, was $211 \mathrm{ml}$ (range, 180-240 ml). The investigatorassessed GEIS indicated that an aesthetic improvement was obtained for $97 \%$ of the breasts at months 1 and 3, for $100 \%$ at month 6 , for $76 \%$ at month $12,74 \%$ at month 18 , and $47 \%$ at month 24 . Figure 3 illustrates an example of breast augmentation after Macrolane injection.

The most commonly reported adverse events were anticipated postinjection reactions such as injection-site pain (29 events) and injection-site reactions (18 events), described as swelling, redness, or hardness. These events typically were of mild to moderate intensity and persisted for up to 2 weeks. The most commonly reported cosmetic adverse events were implant palpability and nodules. Two patients had the implant removed: one due to capsular contraction and one due to inflammatory symptoms. Importantly, the injected material was easily removable by aspiration. A simple remedy for capsule formation was the use of external manipulation (closed capsulotomy). This old and abandoned technique for correcting capsules around silicone implants is far more acceptable with hyaluronic acid because this naturally occurring substance will be gradually absorbed. A total of five patients experienced inflammatory symptoms with onset 13 to 47 days after injection. These events were unexpected, and the 
Fig. 3 Breast augmentation by Macrolane injection. a Before treatment. b Three months after treatment. c Six months after treatment
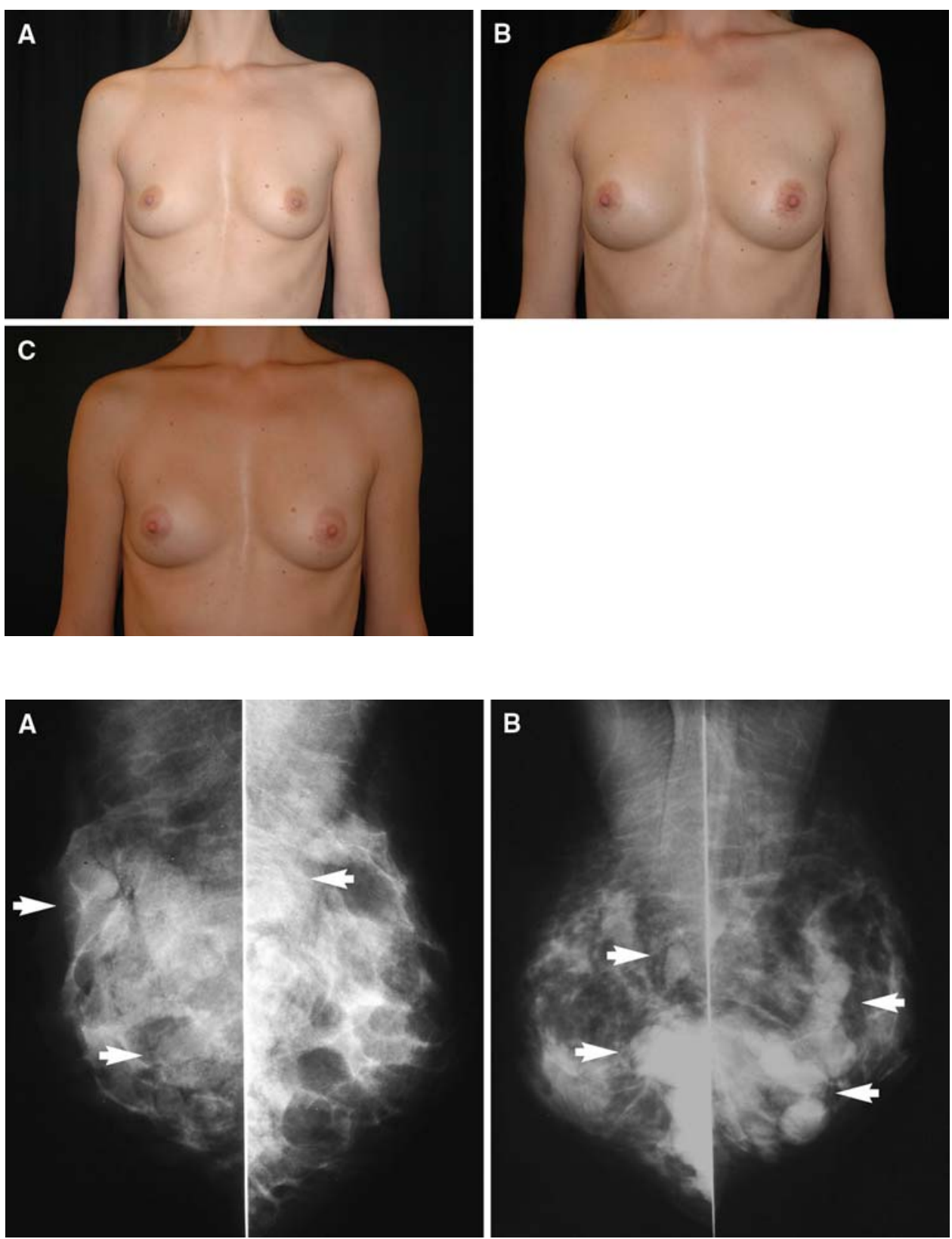

Fig. 4 Mammograms (mediolateral oblique projection) at 12 months from two representative study participants. The arrows indicate the location of the implanted hyaluronic acid gel reason for the accompanying fever was unclear. All cases resolved within 1 week, either spontaneously or after treatment with antibiotics and/or nonsteroidal antiinflammatory drugs [38].

In summary, Macrolane gave satisfactory cosmetic results for at least 18 months for the majority of breasts treated. However, refinement of the gel and an improved implantation technique would enhance the efficacy and safety of the product. Most importantly, MRI and mammography did not show any morphologic alterations in the gland during and after absorption of hyaluronic acid. No cases of microcalcification were observed. The investigators (Tengvar $\mathrm{M}$ et al. [42]) also determined that it was considerably easier to interpret the results of mammography than those obtained with silicone or saline breast implant surgery. The injected hyaluronic acid gel was visible 12 months after treatment in the mammograms of all five patients who had follow-up mammography (i.e., only those older than 35 years). Mammograms from two representative patients (both breasts) are shown in Fig. 4. In two of the patients, the gel was located deeply and partly within the pectoralis muscle. In all cases, the gel was partially superimposed over the glandular tissue. 


\section{Other Treatment Options}

\section{Fat Transfer}

With the advent of liposuction, plastic surgeons were afforded a valuable by-product, namely semiliquid fat, that could be implanted with relative ease using a needle or small cannula [12, 19, 22, 24, 27]. Autologous fat transfer is intuitively appealing. The material is completely biocompatible, requires no pretesting, and usually is available in ample quantities [12]. Implanted fat can be removed if required yet also has the potential to be permanent. Because the ability to remove fat from sites of excess and to implant it into sites of deficiency allows the body to be sculpted, fat grafting has become increasingly popular. The prospective use of adipose tissue stem cells in tissue rejuvenation after implantation also has been investigated recently $[30,34]$.

However, fat grafting is not without its disadvantages. Infection is always possible with surgical procedures, and damage to local nerves, muscles, glands, and blood vessels is a possibility during harvesting. Compared with allogeneous injectable products, the procedure is time consuming and expensive, with unpredictable efficacy, and often is associated with pronounced swelling of the recipient tissues. A number of studies also have reported disappointing long-term survival rates for implanted fat, relatively low rates for long-term patient satisfaction, and excessive growth of the transplanted fat $[12,18,25,32]$. Furthermore, fundamental questions remain regarding the optimal harvesting site, processing technique, and most effective injection technique [9].

Free fat grafts have been used successfully to create volume in facial, reconstructive, and cosmetic surgery [14, 29]. A recent retrospective study of fat transplantation to the buttocks and legs showed that fat grafts were able to live and persist in patients, growing if the patient gained weight in the implanted area and not losing circumference when weight was lost [14]. The longevity of results achieved with free fat grafts is the principal advantage of the procedure. Transplanting a segment of fat causes less trauma to the graft and allows blood vessels to remain intact within the fat graft. Moreover, studies indicate reduced tissue loss and improved graft survival. However, free fat grafts require an appropriate donor site and are not suitable for many patients or indications. Furthermore, segmental fat transfer requires donor- and recipient-site incisions and has the potential for scar visibility [22]. The procedure is more time consuming and costly than injectable fat transfer, so it is not generally performed for purely cosmetic reasons.
Flap Surgery

Flap surgery can be used to create substantial volume for areas of deficiency, usually those arising from trauma (injury or surgery), tumor removal, and burns [4, 23]. For example, in breast reconstruction, the latissimus dorsi muscle flap can be used without significant loss of function. It can be moved into the breast defect while still attached to its blood supply under the axilla. Flap surgery often involves complex procedures associated with donor-site morbidity and considerable scarring, which are highly significant drawbacks to such surgery. It is therefore not an appropriate option for patients considering a procedure to create modest amounts of volume for purely aesthetic improvement.

\section{Silicone Implants}

The placement of silicone implants can provide long-lasting correction and substantial volume, hence their widespread use for breast augmentation. However, as with any invasive procedure, complications after implant surgery are not uncommon. It also is important to note that irrespective of how the implant is constructed or the hardness of the gel used, reoperation can be expected in a relatively large proportion of cases. Recent reports indicate that the risk of complications within the 3-year period after implantation is as high as $50 \%$ with some silicone implants [13]. Generally, silicone implants are not useful for correcting smaller concavities such as irregularities after liposuction or small scars.

\section{Injectable Silicone}

Use of medical grade silicone to repair complicated retinal detachments is approved by the regulatory authorities in both the United States and the European Union. Its off-label use for cosmetic purposes also has been explored [8]. Injection of silicone elicits a chronic inflammatory reaction, with giant cell formation and encapsulation of the injected product in fibrous tissue, thereby creating volume [17].

The use of injectable silicone has been hampered by adverse effects such as infection, palpable nodule formation, granuloma formation, migration, and silicone embolism [17]. However, its proponents claim that it is easy to use, long-lasting, and low in cost, and that high rates of complications usually are associated with the improper use of industrial grade silicone injected by unlicensed or unskilled practitioners [35]. Nevertheless, reports in the peer-reviewed literature to support its use for correction of large-scale volume deficiencies in the body are lacking. 
Polyalkylimide Gel

Polyalkylimide gel (Bio-Alcamid; Polymekon Laboratories, Italy) received a CE mark in 2001 for use to create volume in both the face and body for cosmetic purposes. A recent review stated that the product is biocompatible, is easy to inject and remove, does not migrate, and can be used for correction of slight to very serious aesthetic defects [11, 39]. However, despite these suggestions, BioAlcamid does not currently have FDA approval.

The gel has been used to repair muscular defects after trauma, to augment the buttocks, and to correct postpoliomyelitis amyotrophy of the calves and pectus excavatum as well as irregularities after liposculpture and scar depressions [11]. It also has been used for a wide range of cosmetic defects of both the face and body, with high levels of patient satisfaction reported [28]. However, given the potential permanency of the gel and various reports of serious complications such as granuloma formation [21], long-term studies of the agent are required to confirm its safety and efficacy.

\section{Polyacrylamide Gel}

Polyacrylamide hydrogel is a nonresorbable sterile "watery" injectable gel (Aquamid; Contura, Soeborg, Denmark). Aquamid received its CE mark for soft tissue facial augmentation and corrections in 2001, which was extended in 2003 to include soft tissue corrections of the body. However, Aquamid does not currently have FDA approval. High rates of patient satisfaction have been reported for Aquamid treatment of facial contour deformities or soft tissue deficiencies caused by aging, acne, trauma, and surgery [43]. However, no studies on the safety and efficacy of this treatment for body contour deformities have been published.

\section{Polymethylmethacrylate}

Artecoll (Artes Medical Inc., San Diego, USA), composed of nonbiodegradeable polymethylmethyacrylate particles and bovine collagen, generally is recommended for use in the face. After deep dermal injection, the bovine collagen is broken down and replaced by endogenous collagen. Renamed Artefill, the product achieved FDA approval in 2006, although $21 \%$ of patients injected in the registration study experienced adverse events [7] and incidences of late-onset granuloma formation have been reported [1, 41]. Skin testing also is required with Artefill because the collagen in the product is of animal origin.

\section{Discussion}

The skilled plastic surgeon has a wide range of techniques and products available to create volume in the body. Although the type of defect in question very often limits the selection of interventions available, it is a reasonable assumption that where possible, patients prefer minimally invasive procedures over more drastic interventions. This assertion is supported by the remarkable growth in the number of minimally invasive procedures performed. Although the data do not demonstrate that minimally invasive procedures are replacing surgical treatments, the greater availability and choice of procedures appear to have stimulated increased demand [3].

Minimally invasive procedures offer several benefits. They can be performed using local anesthesia, thus reducing the risk of complications arising from general anaesthesia, and do not require hospitalization. Because the area of open tissue exposed is limited, the risk of serious infections is consequently reduced. Given that many patients seek augmentation for purely cosmetic purposes, avoiding the hospital environment is clearly desirable. Because the extent of trauma is less than with invasive procedures, recovery times tend to be shorter, and the patient can return to his or her normal routine far more quickly. There also may be less requirement for pain management, and patients usually can cope using over-thecounter remedies.

Injectable products also can offer the advantages of predictable, persistent correction through reproducible implantation techniques providing the physician has a thorough understanding of available products and their indications/contraindications and limitations [26]. Patients may find the relatively rapid results offered by injectable products inherently appealing, particularly if, as in the case of autologous fat transfer or hyaluronic acid injections, a natural material is implanted.

Fat transfer is the only minimally invasive treatment option for body recontouring that has gained widespread acceptance. In many ways, fat is an ideal filler. It is nonmigratory, noncarcinogenic, and nonteratogenic, with a low potential for abuse or misuse [26]. When used with the correct technique, it also can provide long-lasting results. However, the unpredictability of results, the uncertainties surrounding longevity, and the requirement for donor material may detract from the appeal of fat transfer. Donor material, unlike fat transfer, is not required with other injectable products, so these treatments may be more suitable for those who do not wish to undergo, or are unsuitable for, liposuction.

Although nonresorbable fillers such as Aquamid and Bio-Alcamid have shown promise, it is noteworthy that 
neither product has gained widespread acceptance among cosmetic surgeons. In two small pilot studies, the NASHA gel product Macrolane demonstrated potential for use in body recontouring and breast augmentation. An improved product, Macrolane VRF, has recently received European approval for breast enhancement, volume restoration, and contouring of body surfaces. Macrolane VRF was developed in part as a direct response to concerns that arose in these pilot studies, and no safety concerns have been raised with the use of this gel formulation.

Macrolane VRF offers several distinct advantages over permanent fillers. Because it is a natural product, NASHA gel has a good safety record when used cosmetically, and although results last up to 18 months [37], the product is nonpermanent, so long-term side effects are less likely than with nonresorbable products. If necessary, Macrolane is easily removable by aspiration. In addition, administration is a minimally invasive procedure, resulting in less downtime for patients and a shorter recovery time than traditional surgical methods.

The use of Macrolane VRF for breast augmentation perhaps holds the greatest promise. Because breasts are seen simultaneously as a marker of womanhood, a visual signifier of female sexuality synonymous with femininity, and essential for nurturing infants, it is not surprising that a great emphasis is placed on their appearance [33]. Furthermore, the current feminine ideal is one of a body both slim and large-breasted. Given that breasts are composed largely of adipose tissue, few women can naturally achieve this ideal. Perhaps for these reasons, breast augmentation currently is the most widely performed surgical cosmetic procedure, and its popularity is growing. Since 2000 , the annual number of performed procedures has risen by $55 \%$ [3].

Dissatisfaction with breast size and shape generally motivates consideration of breast augmentation surgery [40]. In one study, by the age of 18 years, more than onethird of women expressed dissatisfaction with their breast size [33]. Among this huge number of potentially dissatisfied women, some consider augmentation surgery, but only a small proportion of these commit to undergo the procedure. However, if a minimally invasive option were to become widely available, it would offer women reluctant to undertake the risks of surgery the opportunity to achieve moderately increased breast size. It is therefore noteworthy that although the experience of injecting Macrolane into the female breast currently is limited, early results are promising and warrant further investigation.

In conclusion, the expanding array of products and techniques available has widened the scope of what can be achieved by adding volume to areas of the body. Hyaluronic acid has been specifically developed for minimally invasive volume enhancement, including facial tissue augmentation and breast enhancement. It is well tolerated, with predictable long-lasting results. As patients continue to opt for nonsurgical procedures that offer predictable results, the development of minimally invasive products is greatly welcomed.

Acknowledgment The hyaluronic acid studies discussed in the text were sponsored by Q-Med.

Open Access This article is distributed under the terms of the Creative Commons Attribution Noncommercial License which permits any noncommercial use, distribution, and reproduction in any medium, provided the original author(s) and source are credited.

\section{References}

1. Alcalay J, Alkalay R, Gat A, Yorav S (2003) Late-onset granulomatous reaction to Artecoll. Dermatol Surg 29:859-862

2. ASAPS: ASAPS 2006 Statistics on Cosmetic Surgery. Retrieved April at http://www.surgery.org/download/2006QFacts.pdf. Accessed 6 Feb 2009

3. American Society of Plastic Surgeons: Cosmetic and Reconstructive Procedure Trends. Retrieved 2008 at http://www. plasticsurgery.org/Media/Statistics.html. Accessed 6 Feb 2009

4. Baumeister S, Germann G, Giessler G, Dragu A, Sauerbier M (2004) Reconstruction of burned extremities by free flap transplantation. Chirurg 75:568-578

5. Born T (2006) Hyaluronic acids. Clin Plast Surg 33:525-538

6. Bosniak S, Cantisano-Zilkha M (2001) Restylane and perlane: a six-year clinical experience. Operative Tech Oculoplast Orbital Reconstr Surg 4:89-93

7. Broder KW, Cohen SR (2006) ArteFill: a permanent skin filler. Expert Rev Med Devices 3:281-289

8. Broder KW, Cohen SR (2006) An overview of permanent and semipermanent fillers. Plast Reconstr Surg 118:7S-14S

9. Butterwick KJ, Nootheti PK, Hsu JW, Goldman MP (2007) Autologous fat transfer: an in-depth look at varying concepts and techniques. Facial Plast Surg Clin North Am 15:99-111, viii

10. Carruthers A, Carey W, De Lorenzi C, Remington K, Schachter D, Sapra S (2005) Randomized, double-blind comparison of the efficacy of two hyaluronic acid derivatives, restylane perlane and hylaform, in the treatment of nasolabial folds. Dermatol Surg 31:1591-1598, discussion 1598

11. Claoue BL, Rabineau P (2004) The polyalkylimide gel: experience with Bio-Alcamid. Semin Cutan Med Surg 23:236-240

12. Coleman SR (2006) Structural fat grafting: more than a permanent filler. Plast Reconstr Surg 118:108S-120S

13. Cunningham B (2007) The Mentor Core study on silicone MemoryGel breast implants. Plast Reconstr Surg 120:19S-29S, discussion 30S-32S

14. de Pedroza LV (2000) Fat transplantation to the buttocks and legs for aesthetic enhancement or correction of deformities: long-term results of large volumes of fat transplant. Dermatol Surg 26:1145-1149

15. DeLorenzi C, Weinberg M, Solish N, Swift A (2006) Multicenter study of the efficacy and safety of subcutaneous non-animalstabilized hyaluronic acid in aesthetic facial contouring: interim report. Dermatol Surg 32:205-211

16. Duranti F, Salti G, Bovani B, Calandra M, Rosati ML (1998) Injectable hyaluronic acid gel for soft tissue augmentation: a clinical and histological study. Dermatol Surg 24:1317-1325

17. Ellis DA, Segall L (2007) Review of non-FDA-approved fillers. Facial Plast Surg Clin North Am 15:239-246, vii 
18. Eremia S, Newman N (2000) Long-term follow-up after autologous fat grafting: analysis of results from 116 patients followed at least 12 months after receiving the last of a minimum of two treatments. Dermatol Surg 26:1150-1158

19. Fagrell D, Enestrom S, Berggren A, Kniola B (1996) Fat cylinder transplantation: an experimental comparative study of three different kinds of fat transplants. Plast Reconstr Surg 98:90-96, discussion $97-98$

20. Frank P, Gendler E (2001) Hyaluronic acid for soft tissue augmentation. Clin Plast Surg 28:121-126

21. Gomez-de la Fuente E, Alvarez-Fernandez JG, Pinedo F, Naz E, Gamo R, Vicente-Martin FJ, Lopez-Estebaranz JL (2007) Cutaneous adverse reaction to Bio-Alcamid implant. Actas Dermosifiliogr 98:271-275

22. Guyuron B, Majzoub RK (2007) Facial augmentation with core fat graft: a preliminary report. Plast Reconstr Surg 120:295-302

23. Heymans O, Verhelle N, Van Zele D (2003) Coverage of defects: principles. Rev Med Liege 58:695-700

24. Illouz YG (1985) Liposuction: the Franco-American experience. Medical Aesthetic, Beverley Hills, CA

25. Kaufman MR, Bradley JP, Dickinson B, Heller JB, Wasson K, O'Hara C, Huang C, Gabbay J, Ghadjar K, Miller TA (2007) Autologous fat transfer national consensus survey: trends in techniques for harvest, preparation, and application, and perception of short- and long-term results. Plast Reconstr Surg 119:323-331

26. Klein AW (2006) Soft tissue augmentation 2006: Filler fantasy. Dermatol Ther 19:129-133

27. Kononas TC, Bucky LP, Hurley C, May JW Jr (1993) The fate of suctioned and surgically removed fat after reimplantation for soft-tissue augmentation: a volumetric and histologic study in the rabbit. Plast Reconstr Surg 91:763-768

28. Lahiri A, Waters R (2007) Experience with Bio-Alcamid, a new soft tissue endoprosthesis. J Plast Reconstr Aesthet Surg 60:663667

29. Levine JL, Soueid NE, Allen RJ (2005) Algorithm for autologous breast reconstruction for partial mastectomy defects. Plast Reconstr Surg 116:762-767

30. Lu F, Mizuno H, Uysal CA, Cai X, Ogawa R, Hyakusoku H (2008) Improved viability of random pattern skin flaps through the use of adipose-derived stem cells. Plast Reconstr Surg 121:50-58

31. Matarasso SL, Carruthers JD, Jewell ML (2006) Consensus recommendations for soft-tissue augmentation with nonanimal stabilized hyaluronic acid (Restylane). Plast Reconstr Surg 117:3S-34S, discussion 35S-43S

32. Miller JJ, Popp JC (2002) Fat hypertrophy after autologous fat transfer. Ophthal Plast Reconstr Surg 18:228-231

33. Millsted R, Frith H (2003) Being large-breasted: women negotiating embodiment. Women Stud Int Forum 23:455-465

34. Moseley TA, Zhu M, Hedrick MH (2006) Adipose-derived stem and progenitor cells as fillers in plastic and reconstructive surgery. Plast Reconstr Surg 118:121S-128S

35. Narins RS, Beer K (2006) Liquid injectable silicone: a review of its history, immunology, technical considerations, complications, and potential. Plast Reconstr Surg 118:77S-84S

36. Narins RS, Brandt F, Leyden J, Lorenc ZP, Rubin M, Smith S (2003) A randomized, double-blind, multicenter comparison of the efficacy and tolerability of Restylane versus Zyplast for the correction of nasolabial folds. Dermatol Surg 29:588-595

37. Narins RS, Dayan SH, Brandt FS, Baldwin EK (2008) Persistence and improvement of nasolabial fold correction with nonanimalstabilized hyaluronic acid 100, 000 gel particles/mL filler on two retreatment schedules: results up to 18 months on two retreatment schedules. Dermatol Surg 34(Suppl 1):S2-S8

38. Q-Med AB: Data on File (2007) Uppsala, Sweden

39. Ramires PA, Miccoli MA, Panzarini E, Dini L, Protopapa C (2005) In vitro and in vivo biocompatibility evaluation of a polyalkylimide hydrogel for soft tissue augmentation. J Biomed Mater Res B Appl Biomater 72:230-238

40. Sarwer DB (2007) The psychological aspects of cosmetic breast augmentation. Plast Reconstr Surg 120:110S-117S

41. Sidwell RU, Mc LJN, Francis N, Bunker CB (2006) Cutaneous sarcoidal granulomas developing after Artecoll facial cosmetic filler in a patient with newly diagnosed systemic sarcoidosis. Clin Exp Dermatol 31:208-211

42. Tengvar M, Hedén P, Olenius M (2008) Breast augmentation with stabilized hyaluronic acid-based gel of nonanimal origin: visualization of tissue behind the implants. International Master Course on Aging Skin, Paris

43. von Buelow S, Pallua N (2006) Efficacy and safety of polyacrylamide hydrogel for facial soft-tissue augmentation in a 2year follow-up: a prospective multicenter study for evaluation of safety and aesthetic results in 101 patients. Plast Reconstr Surg 118:85S-91S 